International Journal of Linguistics, Literature and Translation

ISSN: 2617-0299 (Online); ISSN: 2708-0099 (Print)

DOI: 10.32996/ijltt

Journal Homepage: www.al-kindipublisher.com/index.php/ijltt

IJLLT

\title{
How Might Cognitive Factors Affect Iranian EFL Learners' Response to Feedback Provided on Writing? An Individual Differences Perspective
}

\author{
Khalil Sazideh ${ }^{\mathbf{9}}$ (D) and Omid Mallahi ${ }^{2} \mathbf{8}$ (D) \\ ${ }^{1}$ Department of English language, Minab Branch, Islamic Azad University, Minab, Iran \\ ${ }^{2}$ Assistant Professor of TEFL, Department of English Language Teaching, University of Hormozgan, Bandar Abbas, Iran \\ $\triangle$ Corresponding Author: Omid Mallahi, E-mail: o.mallahi@hormozgan.ac.ir
}

\author{
ARTICLE INFORMATION \\ Received: April 02, 2021 \\ Accepted: May 17, 2021 \\ Volume: 4 \\ Issue: 5 \\ DOI: 10.32996/ijllt.2021.4.5.3
}

\section{KEYWORDS}

Feedback, individual differences, language learning aptitude, working memory

\section{ABSTRACT}

The researchers exploring the effectiveness of feedback have normally contrasted groups of learners receiving different types of feedback treatments. However, since there are always individual responses to any pedagogical treatment within a group of students and the effects of feedback can vary significantly even in participants receiving the same kind of feedback in the same experiment, the present study used a qualitative case study approach and techniques such as narrative construction and qualitative comparative analysis to see how the individuals with different cognitive characteristics (namely, language learning aptitude and working memory) respond to various types of feedback (namely, direct feedback, indirect feedback with error codes and metalinguistic feedback with explanations) provided on linguistic aspects of their writings and how these characteristics might impact their learning from the feedback. The comparison of the students' responses to the feedback provided indicated that different individuals respond to and benefit from the learning potentials of different types of corrective feedback in different and their own unique ways. In fact, the learners having higher levels of aptitude and working memory were better able to resolve their problems and improve their writing as a result of the feedback received. On the whole, the findings of the present study confirm the important role of considering learners' individual characteristics in any pedagogical intervention.

\section{Introduction}

Corrective feedback (CF), defined as evaluative information and judgment provided on the students' linguistic performance, is widely acknowledged to benefit the learners and enhance the quality of their learning (Larsen Freeman, 2003). The body of research conducted in this tradition had focused upon the purposes, processes and effects of feedback and its various features like "degrees of explicitness (direct vs. indirect), timing (immediate vs. delayed), the manner of delivery (e.g., handwritten vs. delivered using technology), the source (self, the teacher, or peers), and even the visual presentation (i.e., the color of feedback)" (Elwood \& Bode, 2014, p. 334). A point worth-mentioning is that corrective feedback has not been a controversy-free issue and its effectiveness has been challenged by scholars such as Truscott $(1996,1999, \& 2009)$ who claimed that error correction is harmful and should be abandoned since it does not always fulfill its potential. On the other hand, cognitive theorists believe that corrective feedback must always accompany instruction since it plays an important role in facilitating the students' engagement and acquisition (Sheen \& Ellis, 2011). In the same vein, most approaches to second language writing pedagogy have specified a primary role for feedback practice and writing instructors in many education institutions around the world have equipped themselves with the knowledge of effective feedback strategies and offer this valuable asset to their learners with the intention of pointing out their errors and resolving their problems while engaging in the act of writing. However, research undertaken regarding the role of feedback in L2 writing classrooms has referred to the fact that "there are no simple [and conclusive] answers to questions such as which activities merit feedback, how and when to give feedback and what the benefits of giving feedback are" (Long \& Richards, 2006, p. xiii). There are also conflicting/indecisive findings in some areas of feedback such as

\section{K C AL-KINDI CENTER $\mathbf{R}$ D FOR RESEARCH AND DEVELOPMENT}

Your gateway to world-class research

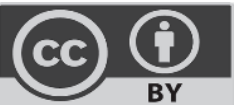

Published by Al-Kindi Center for Research and Development, London, United Kingdom. Copyright (c) the author(s). This open access article is distributed under a Creative Commons Attribution (CC-BY) 4.0 license 
feedback focus, extent and strategy (Ashwell, 2000; Bitchener, 2008; Chandler, 2003; Ellis, 2013; Ferris \& Roberts, 2001; Guénette, 2007; Li, 2010).

Consideration of different learning contexts (e.g., the consideration of the learning atmosphere and instructional methodology variables) and the characteristics and capabilities of different learners (e.g., students' prior educational and language backgrounds, learning style, values and beliefs, motivation, attitude and future goals, and other additional factors) can provide a way out of this controversy (Evans, Hartshorn, McCollum, \& Wolfersberger, 2010; Guénette, 2007; Saadat, Mehrpour, \& Khajavi, 2017) since it is generally believed that different individuals respond to and benefit from the learning potentials of different types of corrective feedback in different and their own unique ways (Kormos, 2012). Ferris, Liu, Sinha, and Senna (2013) also maintain that with few exceptions, the researchers exploring the effectiveness of feedback have contrasted groups of learners receiving different types of feedback interventions. However, since there are always individual responses to any pedagogical treatment within a group of students and the effects of feedback can vary significantly even in participants receiving the same kind of feedback in the same experiment (Ferris, et al., 2013; Santos, Lopez-serrano, \& Manchon, 2010), more investigation must be directed towards examining how learners with different individual differences profiles benefit form and respond to different types of feedback.

\section{Review of the Related Literature}

Ellis (2010) maintains that "The vast bulk of CF studies have ignored learner factors, focusing instead on the relationship and the effect of specific CF strategies and learning outcomes" (p. 339). Ferris (2010) also emphasizes the important role of personal attributes and individual differences in L2 learners' response to corrective feedback by suggesting that "some students benefit more from CF than others, for a variety of reasons such as motivation, learning style, and metalinguistic background knowledge" (p. 197). Storch and Wigglesworth (2010) have further asserted that neglected individual differences such as learners' linguistic backgrounds and affective factors such as their beliefs and attitudes, their levels of motivation and cognitive competencies can influence the outcome of any writing interventions and the learners' uptake and retention of the feedback received to a great extent.

As for the influence of cognitive individual differences on writing, it is hypothesized that learners with high metalinguistic awareness and good deductive skill (i.e., a high aptitude) and those who enjoy from a satisfactory level of working memory capacity are more readily able to adequately devote their attentional resources to different aspects of writing and can more effectively use their metalinguistic knowledge in consciously monitoring the linguistic accuracy of their written texts, noticing and identifying the gaps (and errors) in their grammatical knowledge and engaging more actively in problem-solving process to overcome the linguistic and organizational problems encountered during the writing process (Kormos, 2012). However, few studies have investigated the effect of cognitive and affective factors on the processing of feedback.

In one of these studies, Sheen (2007) explored the relationship between language learning aptitude and written corrective feedback. More specifically, the researcher investigated the relationship between language analytic ability, as one of the main component of language learning aptitude construct, and uptake from direct correction with or without metalinguistic feedback. The findings of study indicated that learners having a high level of aptitude (in this case high language analytic ability) benefited more from feedback under both conditions and they were more advantaged when metalinguistic feedback was offered. It had also been suggested that learners with high level of language aptitude were more readily able to learn and consolidate their L2 knowledge through feedback. In this line of research, Shintani and Ellis (2013) studied how language analytic ability (conceptualized as one main component of language learning aptitude) can influence learners' processing of different written corrective feedback and metalinguistic explanation. The findings of the study pointed to the fact that language analytic ability was effective in the processing of both metalinguistic and direct feedback; however, this influence was dependent upon some considerations such as "type of feedback, whether learners are asked to revise, and the nature of grammatical target" (p. 118).

It is also hypothesized that L2 writers with different working memory (WM) capacities might process and benefit from the learning potentials of different types of feedback in different ways. In fact, it is maintained that WM may shape, explain, and predict the way that learners respond to corrective feedback (e.g., Mackey, et al., 2010; Trofimovich, Ammar, \& Gatbonton, 2007). For example, Payne and Whitney (2002) have found that learners with high working memory capacity benefit more from feedback in face-to-face interaction and produce more modified output, whereas those with low working memory capacity benefit more from feedback delivered via computer-mediated communication.

Some case studies have been reported in the literature which have used think-aloud and/or retrospective interviews to closely examine individual student writers' responses to written corrective feedback (e.g., Ferris, et al., 2013; Hyland, 2011; Storch \& Wigglesworth, 2010). For example, Ferris, et al., (2013) conducted a multiple-case longitudinal study in which ten ESL university students wrote four in-class texts, revised them after receiving written corrective feedback, and participated in retrospective 
interviews after each of the first three writing and revision sessions. More specifically, they tried to analyze the students' selfmonitoring processes while writing and revising their texts and the individual and contextual factors that might affect their writing development. They found that the students considered the applied techniques (focused WCF, revision, and one-to-one discussion about errors) highly beneficial and suggested that "teachers should take a more finely tuned approach to corrective feedback and that future research designs investigating WCF should go beyond consideration of only students' written products" (p. 307).

Moreover, Rahimi (2015) examined the extent to which L2 learners' field dependency and writing motivation (as two main individual difference variables) could influence their learning from and retention of a teacher's written corrective feedback in the short and long run. The results indicated that there was a strong relationship between field independence style and the students' successful short-term and long-term retention of corrections in the subsequent writings; however, writing motivation could only influence and facilitate the short-term retention of corrective feedback. Mallahi (2019) explored how learners with different levels of self-efficacy in writing responded to various types of corrective feedback provided on the linguistics aspects of their written texts. The results of a qualitative comparative analysis of the learners' performances confirmed that each individual can benefit from the learning potential of corrective feedback in different and unique ways. Han and Hyland (2019) explored two students' emotional reactions to teacher WCF and found that these students experienced different discrete emotions with varying object foci, valence, and activation, and these emotions fluctuated in various stages of writing especially in revision process. The researchers further recommended that academic writing teachers "should reflect on the appropriateness of their WCF strategies in local contexts, invite students to express and reflect on their WCF-evoked emotions, and increase students' awareness of the value of academic emotions" (p. 29).

Furthermore, Zheng, Yu and Liu (2020) intended to understand the pattens of low-proficiency students' engagement with teacher corrective feedback in writing by conducting an in-depth case study on two Chinese LP students. After analyzing teacher WCF, students' written drafts, their immediate oral reports and retrospective interviews, the researchers found that "their engagement was distinctively different in terms that one's engagement was relatively extensive, especially in the affective aspect, but the other's engagement was at a relatively limited level, characterized by negative emotions and scant cognitive engagement" (p. 1). Han and Hyland (2015) also highlighted the role of IDs in learners' multi-dimensional aspects of cognitive, behavioral, and affective engagement with WCF. In the same vein, Han (2018) investigated how learner and contextual factors can influence individual learners' engagement with WCF in L2 classrooms. By adopting an ecological heuristic perspective to conduct the study and after analyzing the collected data from multiple sources such as students' writing, verbal reports, interviews, field notes, and class documents, he maintained that individual learners' engagement with WCF can be understood "as a process of perceiving and acting upon embedded learning opportunities afforded by WCF, and highlight the importance of establishing an alignment between affordances and learner agency to enhance individual students' engagement with written feedback (p. 1).

As the investigation of the literature revealed how the individual differences variables influence the use of feedback is still an under-researched area and few studies have explored the nature and effects of these individual differences (especially aptitude and working memory) within the subfield of writing. Saadat, et al., (2017) also argued that "research on the interaction between individual differences and writing feedback is still at its infancy and there is still much to be learned in this area" (p. 86). Benson and DeKeyser (2018) maintain that "carefully controlled experiments on written CF that systematically explore various individual difference factors are relatively few" (p. 4). Consequently, due to the importance of individual difference variables in how the individuals respond to different types of feedback, more research is needed to explore the relationship between individual difference variables and specific corrective feedback strategies targeting specific language features within more authentic classroom practices. In the same regard, the present study intends to answer the following research questions:

1. How do individuals with different cognitive profiles (that is, aptitude and working memory) respond to and learn from different types of feedback (namely, direct feedback, indirect feedback with notations and metalinguistic feedback) provided on linguistic aspects of their writing (that is, structure, vocabulary and cohesion)?

2. What kind of feedback strategy do the students prefer more and why?

\section{Method of the Study}

The present endeavor used a case study approach and attempted to experimentally explore how learners with different individual differences profiles (that is, different levels of aptitude and working memory) respond to and learn from different kinds of feedback (namely, direct feedback, indirect feedback with notations and feedback with metalinguistic explanations) provided on linguistic aspects of writing. The 'case study' is the study of the "particularity and complexity of a single case" (Stake, 1995, p. xi). Dörnyei (2007) further asserts that "case study is not a specific technique but rather a method of collecting and organizing 
data so as to maximize our understanding of the unitary character of the social being or object studied" (p. 152). Generally, a narrative was constructed for each individual and a kind of qualitative case-by-case comparison (i.e., Qualitative Comparative Analysis) was adopted in this phase of the study, which is further elaborated upon below.

Though case studies have been rare in research on corrective feedback in writing, several researchers have utilized this methodology effectively for studies that looked more broadly at teacher commentary and its impact on subsequent student writing (e.g., Goldstein \& Conrad, 1990; Patthey-Chavez \& Ferris, 1997), studies which have examined various aspects of L2 writers' responses to teachers' written feedback (e.g., Hyland, 1998; Hyland \& Hyland, 2001, 2006), studies which have examined variation in case study participants' willingness and ability to revise their writing after receiving a teacher's written commentary (e.g., Conrad \& Goldstein, 1999) and studies which have investigated the extent to which L2 learners' individual differences (e.g., formal knowledge of language, field dependency and writing motivation) influence their monitoring behavior during the writing process and predict their retention of a teacher's written corrective feedback in the short and long run (e.g., Ferris, et al., 2013; Rahimi, 2015). These case studies on teachers' corrective feedback and learners' response have provided some insights which inform and influence the design and procedures of the current study: (1) Teachers must also pay attention to different learners' behaviors while providing them with corrective feedback since individual student writers respond differently to teacher feedback; (2) A number of other factors like the learners' L1 background, their cognitive and affective individual predispositions and factors such as social and pedagogical context might influence the way learners consider and apply feedback they have received. On the whole, this body of case study work on teacher response to student writing provided models for our own research design. Another important point is that this was a naturalistic study, so the instructor taught writing and gave feedback exactly as he would have if any research endeavor had not been present. So, the data included the texts written by the students and the teacher's feedback on these drafts.

\subsection{Participants and setting}

In order to investigate how leaners with different cognitive characteristics respond to and learn from different types of feedback, the researchers chose the students of an essay writing course in University of Hormozgan, Iran. The class was held by one of the researchers during the whole semester and the students received instruction on different methods of supporting ideas and practiced how to write expository and argumentative essays in English. Due to pedagogical concerns and ethics of instruction, all twenty-two students in the class received feedback on different aspects of writing after completing their assignments. However, through the purposive sampling technique, only 4 students, who had fully completed all their assignments and received the intended feedback, were selected as the main participants of the study. More specifically, two students as the representative of individuals with High- and Low-level aptitude scores and two students receiving High and Low scores on a working memory test were selected as the participants of the study. In other words, based on the design of the study, they were treated as individual cases and on the basis of their cognitive (aptitude and working memory) characteristics were matched with each other and their individual profiles were compared in terms of how they responded to different types of feedback and how their individual characteristics inhibited or facilitated their learning from and retention of various types of feedback.

\subsection{Instruments used to assess the students' cognitive characteristics 3.2.1. Foreign language learning aptitude test}

THE COLLEGES OF OXFORD UNIVERSITY CLASSICS LANGUAGE APTITUDE TEST (Specimen of Written Test at Interview Issued 2010) was used to assess Iranian EFL learners' aptitude in learning a second language. This instrument aims at measuring the extent to which EFL learners have the required potential to pursue and go through the challenging process of learning a second language. The test contains three parts targeting the sub-constructs assumed to represent foreign language learning aptitude and measuring the students' ability in paired associates, verbal intelligence and grammatical sensitivity. In order to ease and ensure the students' understanding of the test and to make the test more valid for use by Iranian EFL learners, the instructions were translated into Persian.

\subsubsection{Working memory test}

A computerized Persian version of reading span test (RST) developed by Shahnazari (2011) was used to measure the participants' working memory capacity since it is believed that working memory is language independent and in order to avoid conflating WM and L2 proficiency must be conducted in the students' mother tongue (Miyake \& Friedman, 1998). In the administration session, each individual student was required to read sets of sentences (a total of 64 items: 10 practice session sentences and 54 test sentences) on a computer screen in PowerPoint format and report on the semantic acceptability of each sentence (processing assessment), and then recall the final word of each sentence when prompted (storage assessment). In order to facilitate the students' response to this test, the researcher designed a sheet including some instructions and examples for how to perform on the test and a set of slots to enable the students to write their responses regarding the semantic plausibility of the sentences and the recalled words for each set of the sentences. 


\subsection{Writing assignments and feedback offered}

As was previously mentioned, the students received instruction on different methods of paragraph development and practiced writing expository and argumentative essays. Their written assignments and the feedback received served as the main data of the study based on which an individual profile/narrative was constructed for each student.

The first assignment students were required to write was a descriptive paragraph for which they described either a place they have visited or a person they are familiar with. After completing and delivering the assignment, the students received direct feedback which involves reformulating and rewriting the learners' texts while attending to errors in the linguistic aspects of their texts (Thornbury, 1997). The second assignment was a cause and effect paragraph for which the students were required to write about the causes and effects of some common issues in their lives like causes of car accidents, effects of women working outside home, etc. For this assignment, the students benefited from indirect feedback with annotations which refers to the use of codes marking the types of errors made by the learners (Storch \& Wigglesworth, 2010). Subsequently, they wrote a comparison and contrast paragraph for which they received metalinguistic feedback. In metalinguistic explanation, some negative evidence or (implicit) clues as to the rules of language are provided for the learners to enable them to understand the nature of errors committed and correct the erroneous parts. Metalinguistic feedback is defined by Lyster and Ranta (1997, as cited in Ellis, Loewen, \& Elarm, 2009, p. 304) as "comments, information, or questions related to the well-formedness of the learner's utterance".

A point worth-mentioning is that after receiving feedback for each assignment, the students were required to reflect upon the feedback and try to revise their texts or correct their mistakes accordingly. The students also completed two expository and argumentative essays which served as the standpoint to see whether they have learnt anything from and incorporated the feedback received while performing on the subsequent tasks or not.

\subsection{Procedure of data collection and analysis}

For the purpose of the current study, the students of an essay writing course were chosen and then their written texts were analyzed for errors in the linguistic and discoursal aspects of the texts produced. Subsequently, these learners were provided with different types of feedback and then they were required to revise their texts based on the feedback received. More specifically, five different texts from each student were collected: a descriptive paragraph, a comparison and contrast paragraph, a cause and effect paragraph, one three paragraphs expository essay and one five paragraph argumentative essay which were written during the classroom sessions. The students received feedback for the first three paragraphs and were required to revise their texts. It is worth-mentioning that we adopted a focused feedback approach in which only the linguistic aspects of the texts (structure, vocabulary and cohesion) produced by the learners were targeted. Targeting only the linguistic aspects of the text can be justified by reference to recent research practice on feedback which has confirmed the effectiveness of a focused approach in which teachers target a selected number of error types in their feedback provision practice compared to the comprehensive feedback which may lead to inconsistent and inaccurate correction due to teachers' fatigue and burn-out and thus having a demotivating effect for the students who are confused and frustrated by many error codes, underlines and corrections in their papers (Lee, 2013; Sheen, Wright, \& Moldawa, 2009).

As for analyzing and reporting the data in this phase, at first the researchers created data files/narratives for each of the 4 students based on their marked and revised texts, their performance on the subsequent tasks which showed their responses and learning from feedback, and their preferences for different types of feedback. The narrative construction approach was selected since it provides a systematic and integrated way to organize the various pieces of information about each individual writer and then to compare the findings with other individuals. In fact, the main written texts and the students' revisions were compared to see how they respond to different types of feedback and the essays served as a stand-point to compare different students' learning and consolidation of corrective feedback provided on the linguistic aspects of writing. In fact, a qualitative comparative analysis (QCA) technique was used to compare the narratives already constructed for the individuals in order to compare the pair's performance, identify general patterns in the data and reach a meaningful interpretation of the patterns displayed by the case study participants who have undergone the treatment process (Schneider \& Wagemann, 2007). Finally, the participants' views and preferences regarding the effectiveness of these different types of feedback were sought using an open-ended survey question: this question asked them which feedback strategy they preferred more and why.

\section{Results of the Study}

\subsection{The contribution of aptitude to the individuals' responses to feedback: Fatemeh vs. Shahryar}

Fatemeh, as the representative of learners with a high level of aptitude, has a rather good competence in writing and for the first assignment, she has effectively combined description and anecdote, as the techniques of support, to describe one of her family members. The content and sequence of presenting the ideas were well-organized as well. She has also used a combination of 
simple and complex sentence structures that are generally error-free. The two main errors that were underlined and explicitly corrected for her were a run-on sentence and a missing past tense marker:

Run-on sentence:

My aunt's family and mine were congratulating this festival and saying hello to each other that in this time, I saw a boy who was tall, thin and has short-black hair.

Explicit correction:

While my aunt's family and mine were congratulating this festival and saying hello to each other, I saw a thin and tall boy with short black hair.

The second assignment was a cause and effect paragraph for which the students received indirect feedback with error codes. Herein, due to the complexity of the task and the tension she might have felt while completing the task in the classroom, Fatemeh has committed two errors in sentence structure (SS) and five errors in form of the verbs (VF/VT) plus some other minor mistakes:

Error and feedback in sentence structure:

Car qualities are so low and even if the driver observes all the rules, but broken device or piece of mechanical structure can cause a disruption and finally an accident. (SS)

Error and feedback in verb forms/tense:

A person who drives a car should be focus (VF) on driving and when s/he talks with cell phone (Com) the amount of focusing in driving process will be reduce (VF) and cause (VF/T) accident.

It is worth-mentioning that after receiving the feedback, the students were required to reflect upon the feedback received, ask their questions about the error codes to remove any vagueness in their understanding of the codes and consequently correct their mistakes and even revise the whole drafts.

For the third assignment, the students were required to write a comparison and contrast paragraph and received metalinguistic feedback with comments and explanation as the feedback technique. Again Fatemeh has written a rather good text in terms of content and organization, but naturally she has made new types of errors. The reduction in the number of errors in verb forms shows that she has reflected upon the feedback received in the previous assignment and has been careful about this structure while writing this new task. Despite this improvement, she repeats a number of errors in the sentence structure, which can be partly attributed to her attempts in using complex sentence structures.

Errors and metalinguistic feedback in sentence structures:

First one is that, (not an affective introductory clause), s/he does the sport himself. Because most of (missing article) needs (subject-verb agreement) to be exercised, she can practice (what?!! The intended meaning is not effectively expressed).

Although a person involve with this way (Incorrect subordination), not only has wasted his/her time but also money, too (Imprecise parallel structure).

Due to dominance of these types of errors in her text, the teacher-researcher provided further explanations about the structure of English sentences. These points tried to illustrate to her how to move from simple to compound and then to complex sentence structures and how to use parallel structures. My contact with her revealed that she is a very ambitious and conscientious writer who is very concerned about her writing development.

After these three writing tasks, the instructor started teaching principles of expository and argumentative essays and students wrote two essays in these genres. For these assignments, the instructor's feedback mostly focused on the content and organization of ideas and feedback on the linguistic aspects of the texts was only provided when the erroneous parts disrupted the intended meaning. These two essays served as reference points to see whether the students have learnt anything from the feedback received and whether they have been able to keep (i.e., retention of feedback) and transfer this knowledge while performing on new and more complex tasks or not.

As for her performance in the expository essay, Fatemeh has written a well-managed essay which shows her great care and competence in writing. The rewarding point is that despite the fact that she has written a longer text compared to the previous assignments for which the students were required to write a single paragraph, she has managed to write a more conceptually refined and structurally accurate text. In addition, one of her main problems in the previous assignments that was related to the structure and forms of the verbs has been resolved in many cases in this task except for this part: 
Nowadays, earning money and those issues which are related to it are the most challenging part of everyone's life. It has been affect many aspect of human life. If there be a problem in financial aspect of life, it would cause to disrupting comfort and makes stress for those who are involved.

The most interesting point about her performance is her response to the feedback received on the parallel structures which were erroneous in the previous assignment and for which she received thorough metalinguistic feedback with comments and explanations. In order to show her understanding of the feedback, she has purposefully used a parallel structure which ${ }_{L}$ except for the be verb that should have agreed with the subject in terms of person and number ${ }_{L}$ is structurally accurate. This simple point might be considered as evidence for claiming that this participant has learnt and applied the feedback received on the parallel structures:

Not only financial problems but also change of employment are the most stress makers for nowadays people. However, the new pattern of errors which emerged in her text is related to the use of some imprecise vocabularies and lexical expressions. This problem is very common for less competent EFL learners who do not have enough access to authentic English written and spoken texts and as a result use the imprecise equivalents of words and expressions from their first language while producing a communicative output in the second language. For instance, she has written Life is involved challenging issues instead of life is full of or entangled with challenging issues or your mind get in to solve the problem instead of your mind is engaged in solving the problem.

For the final assignment, the students were required to write in a more complex genre, i.e., argumentative essay, which has its specific rhetorical organization and would possibly affect the students' attention and performance on different aspects of writing. This complex task can serve as a stand point to see whether the students can keep and apply what they have learnt from the feedback for a longer time and write a better text or not.

While confirming the efficacy of feedback in enabling the learners to resolve the problematic issues in their performance and to perform better in the subsequent tasks, the performance of Fatemeh in the argumentative essay indicated that complexity of writing tasks also affects students' performance in writing and can influence their learning from feedback. In fact, since the students in this task have been more engaged with the use of appropriate ideas and organization of the content, it is natural to see errors in other aspects of writing. Fatemeh's preoccupation with the organization of higher order levels of meaning has made her commit errors of the same nature (in sentence structure, verb forms and precision of words) but different in forms:

This issue has been effected on most of not only individual life but also society conditions which will be effective on treating future generation.

Children who were faced with such problems and were growed up with this situation will cause bad treatment or some negative bhaviours (shyness) of them and it will arise generation who are going to live in society.

These fluctuations in the performance can possibly be interpreted as her inability to effectively learn from feedback and consolidate this knowledge. Regarding her preference for different types of feedback (namely, explicit correction, indirect feedback with error codes and metalinguistic feedback with comments and explanations), Fatemeh, because of favoring experiential and discovery-oriented approaches to learning prefers indirect feedback with error codes and maintains that: Based on my understanding of myself, I like to understand my mistakes by experience and if I receive direct feedback, I will possibly remember it at that moment but it won't become an experience for me. This type of feedback also does demolish the confidence of the learners.

Shahryar, as the representative of students with low aptitude levels in the present study, has an intermediate competence in writing. As for the descriptive paragraph, he has described one of his friends. Compared to the descriptive text written by Fatemeh which was innovative in content and rather precise in structure, Shahryar's descriptive paragraph is very short and full of grammatical errors. The following are some of the erroneous and run-on sentences in his text that are explicitly corrected:

Erroneous sentence:

My friend is a very genial/affable person, he talks with everyone that meet every where easily, so outgoing. Explicit correction:

My friend is a very genial and outgoing person who easily talks with everyone he meets.

Erroneous sentence:

Although he is very relax person but sometimes he becomes very nervous and angry easily but most of the times he tries to make us laugh with his jokes, he has sense of humor.

Explicit correction:

Despite of being a relax person, he sometimes becomes very nervous and angry. However, he has a good sense of humor and most of the times tries to make us laugh with his jokes. 
The same patterns of errors occurred in the cause and effect paragraph for which he received indirect feedback with error codes: About the roads that are one of the major reasons (MW, Com) we should express that if we don't have good and proper roads (Com) the (Art) more accidents will happen. But the main reason in my idea is the driver itself (WF) (Ro) if she or he consider all the driving rules (Com) absolutely accident will decreases (VF).

In fact, since he is not competent enough in appropriately connecting the ideas with each other, there are many cases of run-on sentences in his texts. Some of the errors can be attributed to his careless and perfunctory manner in writing because it seems that he has not been effectively engaged in the process of writing and has not done any revisions.

The analysis of his performance in the comparison and contrast paragraph indicates that despite some problems like missing punctuation marks, incorrect prepositions, imprecise words, misplaced conjunctive adverbs, etc., he had successfully managed to break his sentences and could write shorter and more precise sentence structures. To put it in another way, previous feedback has possibly urged him to be more careful and try to improve the structure of the sentences.

An idea unit in the comparison and contrast paragraph:

First of all (punctuation mark is missing) with watching sports on TV, we can save our money, time and etc. We can learn the the techniques of players on TV and then use it in real playing by ourselves (try to make it more precise to convey your idea in a better way). On the other hand (this conjunction is used to show contrast not similar ideas) there are also advantages (missing preposition) playing sports yourself. It can help to your healthy (make it more precise) and also you can meet your friends and talk to them.

The possible learning form feedback by this participant was further scrutinized by evaluating his performance in the expository and argumentative essays. Despite some problems in the overall unity and connections of the ideas to each other (i.e., cohesion and coherence) and the existence of some simple and in some cases, imprecise words and expressions in the essays, he has again tried to write shorter and more accurate sentences. Notwithstanding this effort, similar to the performance of the high aptitude learner, there are pieces of evidence of fluctuations in his performance and he has written sentences that are unnecessarily long and suffer from some grammatical mistakes:

An ungrammatical and run-on sentence in the expository essay:

But one point which you should not forget is that you should know your talent and your favorites then go for it and try to be the best in your field and find a suitable and proper job which can rich you in your life so be creative and be hardworking.

An ungrammatical and run-on sentence in the argumentative essay:

As the result of enhance the level of expectations unfortunately the number of divorces has increased in our society and the couples seeking for separation while their children especially in early years of their lives need to be with their parents.

Regarding his preference for different types of feedback, this participant prefers metalinguistic feedback because he thinks by this feedback he could consciously learn rules and he had tried to apply them in his writing.

The comparison of responses of high and low-level aptitude learners to different types of feedback indicated that both learners could learn and apply the specific types of feedback for a short term, but for varying degrees. It was also revealed that the complexity of the task and the students' level of engagement could affect their writing and learning from the feedback. On the whole, it can be asserted that Fatemeh who has a higher level of aptitude and hence a higher level of writing competence, has been able to benefit from the feedback in a more effective way and, as a result of the feedback received had been able to write more refined and complex sentence structures.

\subsection{The contribution of WM to the individuals' responses to feedback: Somayeh vs. Fatemeh}

Somayeh is an upper-intermediate proficiency level student of English Language Teaching. Based on her score on the working memory test, she is considered as a student with high WM capacity. She has written a rather short descriptive paragraph in which the ideas are straightforward and to-the-point. She has used many parallel structures to describe the features of her friend. Almost all these structures, except for one case that is explicitly corrected for her, are grammatically error-free:

An erroneous sentence with parallel structure:

She is short and thin, and a round face, white skin with dark brown eyes.

Explicit correction:

She is short and thin; she has a round face and white skin with dark brown eyes.

The subsequent paragraph that she has written, i.e., cause and effect paragraph, is also well-organized and the ideas are straightforward as well. This might be related to her high working memory capacity and the level of automatization she might 
have reached in writing. However, it is natural to see some local errors that do not greatly disrupt or affect the chain of ideas/meaning in her text:

Maybe some of them when are drunk do driving (SS) which lead (Prep) accidents. Second, terms of establishing (WW) driver license for people somehow (WO) is easy.

She has also made some local level errors, especially in terms of the precision of words and expressions used, in the comparison and contrast paragraph:

The view of cities and buildings seems more beautiful in compared with in (find correct expressions). Long years ago (try to use a more precise expression + use correct punctuation mark) houses and buildings had a simple structure and traditional structure.

For the expository essay, she has written a coherent, well-organized and well-managed text. She has also used a variety of simple, compound and complex sentence structures in this essay; however, there are some cases of local errors in the form of the verbs as well:

Although a lot of people are well-educated, knowledgeable and skillful, they are not successful to find their ideal job to live better. They will deal to a lot of challenges when they begin to find a job for themselves. In spite of have being less job opportunities, there are some effective steps which help you find a good job.

The performance of this participant in the argumentative essay indicates that as the task becomes more complex, the management of different aspects of writing, even for this student who has a high working memory score, becomes more challenging too. As a result, the number of errors increases while performing such complex tasks. The following extract is the introductory paragraph Somayeh had written for the argumentative essay. The main reason for the abundance of errors in this text can be her occupation with the content and sequencing of ideas because the students had been required to briefly include, to the extent possible, all the necessary argumentative moves such as introducing the topic, stating the significance of the topic, presenting and refuting the counterargument and coming up with a decisive thesis statement in this introductory paragraph. Despite her high score in the WM test as an indication of her high WM capacity, she has not been able to give a balanced attention to all aspects of writing in this paragraph and consequently, she has made many errors in the structure of sentences, connections between ideas and choice of words:

This fact is obvious that today media, a large number of TV programs and magazines get into couples' issues which deal to divorce. Definitly divorce has a lot of bad affections that influence either parents or children. However most of people and psychologists believe the children must be supported by parents, so they should stay together. Nonetheless the fact might be true, but if parents stay together bad affections of this cool relationship might influence both the parents and the children. Also the best years of the parent's life and their youth will be lost.

After relieving from this tension, she has written more structurally refined and semantically precise sentences even immediately after this introductory paragraph and in the rest of the essay, which confirm the idea that the complexity of the task can highly affect the precision of writing and the students' learning form and use of the feedback already received.

The first body paragraph in the same argumentative essay:

Those who believe parents should stay together state that the children must be supported emotionally by their parents to go through a normal way of life. To be honest, this opinion sounds logical since in a normal way a child has to live with his family that includes father, mother and the child. In this way, the children feel comfortable. But the more important fact is staying in a cool relationship and behaving in a surface way by parents in very offensive for children. They understand there is no warm and friendly atmosphere in their home. Seeing such a picture in every day's life creates a negative imagination in children's mind. Also they will have a bad mental and emotional pressure.

Regarding her views about different types of feedback received, Somayeh prefers metalinguistic feedback with comments because she thinks that by such a feedback strategy, they can be more directly aware of the aspect of their problems and, thus, can make informed decisions to solve those problems and improve their writing.

Fatemeh is an upper-intermediate proficiency level student of English Language Teaching. Her score in the WM test, which assessed both processing and storage of information, indicated that she has a rather low working memory capacity. In the descriptive paragraph, she is describing her cousin. In this text, the grouping and connection between the ideas that are necessary for creating a coherent text are not well-handled and some of the lexical expressions used are not precise enough. These are the introductory sentences for which she has received explicit correction: 
A person I will always remember is my cousin because of his appearance and gentle manner. The first thing I notice when I look at him is his size. He stands at shoulder height next to me; indeed, he is a head taller than other children his age, and definitly stronger, recently, his father signed his up for football, because it is a good thing the children play football to training for future.

Explicit correction:

A person I will always remember because of his appearance and gentle manner is my cousin. The first thing I notice when I look at him is his height. When he stands next to me, he has a height close to my shoulder. Indeed, , he is a head taller than other children of his age and is definitely stronger. Recently, his father had signed him up in the football team as a training for his future.

Compared to the rather refined text written by the student with high working memory capacity, the analysis of cause and effect paragraph written by this student revealed many grammatical errors from mistakes in spelling to run-on sentences, which have made her whole text ineffective:

There are many reason (PL) why sports teams (WF) are unsuccess or failure (WF)... Also becaus (Spl) of careless (WF) of their managers (Com) the team cannot achieve success and caus (WF) emotion pressur (Spl) and absurd-mindedness (RO) sometimes they are far away from their families and it is the other emotion pressur that bother (AGR) teams that they are do exercises on another country for example (SS).

There are also many grammatical errors in the comparison and contrast paragraph she had written:

... However, playing football is not dangerous as much as wrestling but also they insured in sometimes but a little (is it a correct parallel structure?). They have more facilities and also have good income. Although they are sport and fit your body but they have different condition to achieve tier goals (incorrect subordination + sentence structure needs revision).

Despite receiving thorough metalinguistic feedback with comments, these patterns of errors continued to the expository essay in which the ideas are mixed and most of the sentences are imprecise. The following extract is the introductory paragraph she had written for the expository essay:

Government says that there are just \%20 of young population jobless. It's true or not? is there any jobs or young people search for the jobs that is hard to find for to be luxury today by this special situation of life (hard to find good job) the job seeker must to have those three most important features and well done in prepare a letter of application, conduct an internet job search and perform will in the interview.

Errors of the same nature and her perfunctory and unmotivated manner in writing continues to the argumentative essay which is more complex in nature and demands more sophisticated levels of mental processing. She had written the whole essay in three short paragraphs that are quite inconsequential in terms of the appropriateness of the content and adequacy of the required argumentation. Despite the fact that she had reduced the length of sentences, she had not been able to use the feedback received and could not write a more structurally accurate and semantically refined text. The following extract is the whole text she had written and delivered to the instructor; however, it is not clear whether she had considered it as the introductory paragraph or as the entire essay:

Nowadays the number of divorce has increased in lots of the reason. It must be controlled by systematic organization to have good and health society. According to this reasn the children are the most important part cause this problem can affected them easily and chang their future life.

Some sociologist have their own opinion that tell the parent cause of their child and to keep their family shoulden't be sperate.

Is it an opinion but the issue is not just to keep the form and family member together caus it effect wors. if the problems become worse and intensify it's affect on the emotion and their mental health.

The abundance of grammatical errors in her text indicates that she has not paid any attention to the feedback received and continues to write in her own style. Part of the reason for these problems can be attributed to her inadequate level of competence in writing which cannot be developed by mere feedback and requires a high level of commitment and practice to be improved. Moreover, it seems that she has not been fully engaged in the process of writing, might not have fully noticed and processed the feedback received (i.e., her level of engagement with feedback is low) and only writes whatever comes into her mind without any concerns for the proper organization of ideas or monitoring the structure of sentences.

Regarding the impact of WM on her writing compared to the performance of Somayeh who had a high WM capacity, Fatemeh has a limited control over different aspects of writing and her texts are full of grammatical and syntactic errors. In fact, this low WM capacity has not enabled her to sustain and perform well in writing and to learn from and apply the feedback received in subsequent writing tasks.

Finally, similar to her peer, she prefers metalinguistic feedback because she thinks comments and explanations had made the points more clear for her and she had known the reasons for her errors that could help her know her deficiencies in writing in English. 


\section{Discussion}

After qualitatively comparing the performances of learners with different individual characteristics on different writing tasks and scrutinizing their responses to different types of feedback, a number of considerations and patterns emerged in the data that are presented and discussed here. The initial and the most important observation which can be driven by the findings of the present study is that different individuals respond to and benefit from the learning potentials of different types of corrective feedback in different and their own unique ways (Ferris, 2012; Kormos, 2012; Rahimi, 2015) to the extent that learners having similar individual characteristics might again perform differently while facing the feedback. The finding of the present study also supports Ferris's (2010) conceptualization that "some students benefit more from CF than others, for a variety of reasons such as motivation, learning style, and metalinguistic background knowledge" (p. 197). In fact, the findings of the present are in line with the idea that learners' individual characteristics and contextual factors affect how and to what extent they respond to the teacher's feedback and develop their interlanguage (Ellis, 2010). This different level of engagement and learning from feedback could also be attributed to the individual factors of student beliefs and goals, and contextual factors of student-teacher relationship (Zheng, et al, 2020).

It was also found that learners with higher levels in aptitude and WM had a better response to feedback, albeit to varying degrees. In fact, the student having a higher aptitude score has been able to create tests which are more structurally refined. This finding also confirms the association between aptitude and syntactic knowledge which enables the student writers to engage in the efficient grammatical encoding practice and to write more grammatically accurate and structurally complex texts (Kormos \& Trebits, 2012). Being considered as a dynamic and complex construct, aptitude has also been considered as an important predictor of foreign language learning and students' performance in all language skills (Gilabert \& Munoz, 2010). In line with the findings of present study, Shintani and Ellis (2015) and Benson and DeKeyser (2018) have also highlighted the significant role of language learning analytic ability (as a component of aptitude) on the learners' uptake from direct and metalinguistic feedback. The qualitative analysis of the narratives also confirmed the important role of working memory in planning, execution and monitoring stages of writing which makes huge demands on writers' cognitive processes since the number of things that must be dealt with simultaneously is stupendous. Consequently, writers face cognitive overload while composing a text which negatively affects their level of engagement in the writing process (Flower \& Hayes, 1981; Kellogg,1996) which will definitely affect their retention and use of the feedback received to a great extent. The finding of the present study in terms of the positive role of WM in students' learning from WCF is in line with Li and Roshan's (2019) finding that complex working memory is a positive predictor of the effects of metalinguistic explanation and the effects of direct corrective feedback plus revision. However, they recommended that writing tasks should be adapted so that they can accommodate learners with different working memory ability levels. In other words, their findings highlighted "the value of an interactional approach to the role of individual difference factors, that is, the influence of cognitive factors is not fixed; rather, it depends on whether there is a fit between the processing demands of the learning task and the learners' cognitive strengths" (p. 12).

Despite the fact that the given feedback could, to some extent enhance some of the students' performance in designated aspects of writing, it was not able to resolve all these problems in the students' subsequent texts. This further adds to the debate over the effectiveness of the corrective feedback since some researchers doubt over its potential in improving L2 learners' writing accuracy in their subsequent writings (e.g., Fazio, 2001; Truscott, 1996, 1999, 2004, 2007). In fact, many of the problems found in the students' drafts were related to the students' prerequisite knowledge in grammar and vocabulary which should have already been established. Therefore, effective teaching of vocabulary and grammar as separate courses or complemented with writing can greatly affect the students' accuracy and fluency while writing. The dominant error made by the participants in the present study was related to the sentence structures which were mainly run-on. Rahimi (2009) suggests that this phenomenon stems from the interference of learners' L1 (Persian) and the dominant teaching method, i.e., grammar-translation method, in the EFL context of Iran and could be effectively resolved by teaching correct sentence structures in a more practical way because most Iranian EFL learners consider grammar as a set of rules to be memorized rather than as a tool for generating accurate and fluent communicative output. Moreover, as Hu (2003, as cited in Yang \& Lyster, 2010) believes "the exclusive use of traditional grammar translation approaches is problematic and results in learners who are able to achieve high scores on discrete-point grammar tests yet unable to communicate fluently and accurately in communicative context" (p.236).

There were also some fluctuations in the students' use of feedback while performing on different tasks, yet as Vygotsky (1978) maintains, development and learning involves both progressive and regressive moves, and regressive moves are also helpful in moving the learners forward. In many cases, the students, despite being able to remove some of their mistakes in the following tasks as a result of feedback received, have repeated errors of the same nature in the subsequent tasks. This might also be interpreted as their incompetence in long term retention of the feedback or their inability to effectively incorporate the feedback received. Moreover, the analyses of the students' responses to feedback indicated that most of the learners performed better and mostly incorporated the feedback in the expository essay which served as a standpoint to show short term retention of 
feedback. This finding is in line with the studies that found feedback on the form could help improve students' writing in the short-term (Ashwell, 2000; Fathman \& Whalley, 1990; Ferris \& Roberts, 2001). However, transfer of learning and long-term retention and use of feedback did not occur for the argumentative essay which was structurally more complex. In Robinson's (2001) definition, "task complexity is the result of attentional, memory, and other information processing demands imposed by the structure of the task on the language learner" (p. 29). In fact, the complexity of this task which required balanced attention to various aspects of writing greatly affected the students' performance and their usage of the feedback received. In this case, the complexity of the argumentative essay has been even challenging for the students who have a high working memory score, which confirms the idea that the complexity of the task can highly affect the precision of writing and the students' learning form and use of the feedback already received.

Finally, most of the students prefer metalinguistic feedback and it seems to be more effective feedback providing a methodology for Iranian EFL learners. This finding confirms the general observation that learners have positive attitudes towards teachers' written feedback and expect their instructors to provide them with some feedback and comments on their errors (Erlam, Ellis \& Bastone, 2013; Ferris, 1995; Ferris \& Roberts, 2001; Hyland, 1998; Lee, 2004; Rahimi, 2015). A number of studies have also found that WCF has greater effects when it contains metalinguistic information (Bitchener \& Knoch, 2008, 2010; Gao \& Ma, 2019; Sheen, 2007, 2010; Shintani, Aubrey, \& Donnellan, 2016). However, metalinguistic information varied across studies in terms of how specific it was and how it was delivered (Jang, 2020). In the same regard, as was evident in the analysis of cases, whether and which type of feedback is effective to improve the learners' noticing of and learning from feedback depend on a complex and dynamic interaction of an array of linguistic and individual factors (Storch \& Wigglesworth, 2010). In the same vein, teachers might need to spend more effort when planning and giving CF and consider more effective strategies to meet learners' needs (Ferris et al., 2013; Han \& Hyland, 2015).

\section{Conclusion}

The present study explored how learners with different individual characteristics respond to and learn from different types of feedback provided on linguistic aspects of their texts. The qualitative analyses of the students' written texts and the feedback they had received corroborated the view that different individuals respond to and benefit from the learning potentials of different types of corrective feedback in different and their own unique ways. Feedback could also improve only some aspects of the students' writing and uptake form feedback only occurred for those features that were important for the learners and they paid conscious attention to them. In other words, uptake and learning from corrective feedback is highly dependent on the learners' depth of engagement with errors and their own concerns for their writing development (Storch \& Wiggleworth, 2010; Troia, Harbaugh, Shankland, Wolbers, \& Lawrence, 2013). In fact, student engagement with written corrective feedback is generally believed to correlate positively with academic achievement, language acquisition and writing development (Zhang \& Hyland, 2018). On the whole, the findings of the present study confirm the important role of considering learners' individual characteristics in any pedagogical intervention. In fact, by equipping themselves with the insight and knowledge of the learners' personal attributes and the important role they play in the learning process, teachers would have a chance to better design their instructional methods and make use of the most suitable learning activities that can respond to the individual learners' needs and thus can enhance the quality of their learning.

Funding: This research received no external funding.

Acknowledgments: The reserachers would like to thank the anonymous reviewers who provided insightful comments and suggestions on the first draft and contributed to the betterment of the final draft of the article. We are grateful to all the participants who have contributed to this study.

Conflicts of Interest: The authors declare no conflict of interest.

\section{References}

[1] Ashwell, T. (2000). Patterns of teacher response to student writing in a multiple-draft composition classroom: Is content feedback followed by form feedback the best method? Journal of Second Language Writing, 9(3), 227-257. https://doi.org/10.1016/S1060-3743(00)00027-8

[2] Benson, S., \& DeKeyser, R. (2019). Effects of written corrective feedback and language aptitude on verb tense accuracy. Language Teaching Research, 23(6), 702-726. https://doi.org/10.1177/1362168818770921

[3] Bitchener, J. (2008). Evidence in support of written corrective feedback. Journal of Second Language Writing, 17(2), 102-118. https://doi.org/10.1016/j.jslw.2007.11.004

[4] Bitchener, J., \& Ferris, D. R. (2012). Written corrective feedback in second language acquisition and writing. Routledge.

[5] Bitchener, J., \& Knoch, U. (2008). The value of written corrective feedback for migrant and international students. Language Teaching Research, 12(3), 409-431. https://doi.org/10.1177/1362168808089924

[6] Chandler, J., (2003). The efficacy of various kinds of error feedback for improvement in the accuracy and fluency of L2 student writing. Journal of Second Language Writing 12, 267-296. https://doi.org/10.1016/S1060-3743(03)00038-9

[7] Dörnyei, Z. (2007). Research methods in applied linguistics: Quantitative, Qualitative and Mixed Mehodologies. Oxford University Press.

[8] Ellis, R. (2009). Corrective feedback and teacher development. L2 Journal, 1, 3-18. https://doi.org/10.5070//2.v1i1.9054 
[9] Ellis, R. (2010). A framework for investigating oral and written corrective feedback. Studies in Second Language Acquisition, 32, 335-349.

[10] Ellis, R. (2012). Language teaching research and language pedagogy. Malden, MA: Wiley-Blackwell.

[11] Ellis, R., Loewen, S., \& Erlam, R. (2006). Implicit and explicit corrective feedback and the acquisition of L2 grammar. Studies in Second Language Acquisition, 28, 339-369. https://doi.org/10.1017/S0272263106060141

[12] Elwood, J. A., \& Bode, J. (2014). Student preferences vis-à-vis teacher feedback in university EFL writing classes in Japan. System, 42, 333343. https://doi.org/10.1016/j.system.2013.12.023

[13] Evans, N. W., Hartshorn, K. J., McCollum, R. M., \& Wolfersberger, M. (2010). Contextualizing corrective feedback in second language writing pedagogy. Language Teaching Research, 14(4), 445-463. https://doi.org/10.1177/1362168810375367

[14] Fathman, A. K., \& Whalley, E. (1990). Teacher response to student writing: Focus on form versus content. In B. Kroll (Ed.), Second language writing: Research insights for the classroom (pp. 178-190). Cambridge University Press.

[15] Fazio, L. L. (2001). The effect of corrections and commentaries on the journal writing accuracy of minority-and majority-language students. Journal of Second Language Writing, 10(4), 235-249. https://doi.org/10.1016/S1060-3743(01)00042-X

[16] Ferris, D. (2007). Preparing teachers to respond to student writing. Journal of Second Language Writing, 16(3), 165-193. https://doi.org/10.1016/j.jslw.2007.07.003

[17] Ferris, D. (2011). Treatment of error in second language student writing. University of Michigan Press.

[18] Ferris, D. R. (2002). Treatment of error in second language student writing. University of Michigan Press.

[19] Ferris, D. R. (2003). Response to student writing: Research implications for second language students. Erlbaum.

[20] Ferris, D. R. (2010). Second language writing research and written corrective feedback in SLA: Intersections and practical applications. Studies in Second Language Acquisition, 32, 181-201. https://www.jstor.org/stable/44488126

[21] Ferris, D. R. (2014). Responding to student writing: Teachers' philosophies and practices. Assessing Writing, 19, 6-23. https://doi.org/10.1016/j.asw.2013.09.004

[22] Ferris, D. R., Liu, H., Sinha, A., \& Senna, M. (2013). Written corrective feedback for individual L2 writers. Journal of Second Language Writing, 22, 307-329. https://doi.org/10.1016/j.jslw.2012.09.009

[23] Ferris, D., \& Hedgcock, J. S. (2005). Teacher response to student writing: Issues in oral and written feedback. Teaching ESL Composition: Purpose, Process and Practice, 184-222.

[24] Ferris, D., \& Roberts, B. (2001). Error feedback in L2 writing classes: How explicit does it need to be? Journal of Second Language Writing, 10(3), 161-184. https://doi.org/10.1016/S1060-3743(01)00039-X

[25] Flower, L., \& Hayes, J. R. (1980). The dynamics of composing: Making plans and juggling constraints. In L. Gregg and E. Steinberg (Eds.), Cognitive processes in writing (pp. 31-50).

[26] Gao, J., \& Ma, S. (2019). The effect of two forms of computer-automated metalinguistic corrective feedback. Language Learning and Technology, 23(2), 65-83.

[27] Gilabert, R., \& Muñoz, C. (2010). Differences in attainment and performance in a foreign language: The role of working memory capacity. International Journal of English Studies, 10 (1), 19-42. https://doi.org/10.6018/ijes/2010/1/113961

[28] Goldstein, L., \& Conrad, S. (1990). Student input and the negotiation of meaning in ESL writing conferences. TESOL Quarterly, 24, 443-460. https://doi.org/10.2307/3587229

[29] Guénette, D. (2007). Is feedback pedagogically correct? Research design issues in studies of feedback on writing. Journal of Second Language Writing, 16(1), 40-53. https://doi.org/10.1016/j.jslw.2007.01.001

[30] Han, Y. (2019). Written corrective feedback from an ecological perspective: The interaction between the context and individual learners. System, 80, 288-303.https://doi.org/10.1016/j.system.2018.12.009.

[31] Han, Y., \& Hyland, F. (2015). Exploring learner engagement with written corrective feedback in a

[32] Chinese tertiary EFL classroom. Journal of Second Language Writing, 30, 31-44. https://doi.org/10.1016/j.jslw.2015.08.002

[33] Han, Y., \& Hyland, F. (2019). Academic emotions in written corrective feedback situations. Journal of English for Academic Purposes, 38, 113. https://doi.org/10.1016/j.jeap.2018.12.003.

[34] Hyland, F. (1998). The impact of teacher written feedback on individual writers. Journal of Second Language Writing, 7, $255-286$. https://doi.org/10.1016/S1060-3743(98)90017-0

[35] Hyland, F. (2011). The language learning potential of form-focused feedback on writing: Students' and teachers' perceptions. In R. M. Manchón (Ed.), Learning-to-write and writing-to-learn in an additional language (pp. 159-180). John Benjamins.

[36] Jang, S. (2020). The efficacy of different types of metalinguistic information in L2 written corrective feedback. English Teaching, 75(4), 33-56. https://doi.org/10.15858/engtea.75.4.202012.33

[37] Kellogg, R.T. (1996). A model of working memory in writing. In C. M. Levy \& S. Ransdell (Eds.), The science of writing: Theories, methods, individual differences and applications (pp. 57-71). Lawrence Erlbaum.

[38] Kormos, J. (2012). The role of individual differences in L2 writing. Journal of Second Language Writing, 21(4), $390-403$. https://doi.org/10.1016/j.jslw.2012.09.003

[39] Kormos, J., \& Trebits, A. (2012). The role of task complexity, modality and aptitude in narrative task performance. Language Learning, 62(2), 439-472. https://doi.org/10.1111/j.1467-9922.2012.00695.x

[40] Larsen-Freeman, D. (2003). Teaching language: From grammar to grammaring. Heinle/ Thomson.

[41] Lee, I. (2004). Error correction in L2 secondary writing classrooms: The case of Hong Kong. Journal of Second Language Writing, 13(4), 285312. https://doi.org/10.1016/j.jslw.2004.08.001

[42] Lee, I. (2008). Student reactions to teacher feedback in two Hong Kong secondary classrooms. Journal of Second Language Writing, 17(3), 144-164. https://doi.org/10.1016/j.jslw.2007.12.001

[43] Lee, J. (2013). Can writing attitudes and learning behavior overcome gender difference in writing? Evidence from NAEP. Written Communication, 30(2), 164-193. https://doi.org/10.1177/0741088313480313 
[44] Li, S. (2010). The effectiveness of corrective feedback in SLA: A meta-analysis. Language Learning, 60(2), 309-365. https://doi.org/10.1111/j.1467-9922.2010.00561.x

[45] Li, S., \& Roshan, S. (2019). The associations between working memory and the effects of four different types of written corrective feedback. Journal of Second Language Writing, 45, 1-15. https://doi.org/10.1016/j.jslw.2019.03.003

[46] Mackey, A., Philip, J., Egi, T., Fujii, A., \& Tatsumi, T. (2002). Individual differences in working memory, noticing of interactional feedback and L2 development. In P. Robinson (Ed.), Individual differences and instructed language learning (pp. 181-210). John Benjamins.

[47] Mallahi, O. (2019). Individual Differences in Learning and Corrective Feedback in Writing Skill: A Case for Self-Efficacy Beliefs. Iranian Evolutionary and Educational Psychology Journal, 1(3), 151-161. Doi: 10.29252/ieepj.1.3.151

[48] Miyake, A., \& Shah, P. (1999). Models of working memory: Mechanisms of active maintenance and executive control. Cambridge University Press.

[49] Payne, J. S., \& Whitney, P. J. (2002). Developing L2 oral proficiency through synchronous CMC: Output, working memory, and interlanguage development. Calico Journal, 7-32. https://www.jstor.org/stable/24149607

[50] Rahimi, M. (2009). The role of teacher's corrective feedback in improving Iranian EFL learners' writing accuracy over time: is learner's mother tongue relevant? Reading and Writing, 22(2), 219-243. https://doi.org/10.1007/s11145-008-9139-5

[51] Rahimi, M. (2015). The Role of individual differences in L2 learners' retention of written corrective feedback. Journal of Response to Writing, 1(1), 19-48.

[52] Robinson, P. (2001). Task complexity, cognitive resources, and syllabus design: A triadic framework for examining task influences on SLA. Cognition and Second Language Instruction, 287-318.

[53] Saadat, M., Mehrpour, S., \& Khajavi, Y. (2017). The Role of Individual Difference Factors in Writing Feedback Use and Involvement: A Qualitative Study of Iranian EFL Learners' Perceptions. Khazar Journal of Humanities \& Social Sciences, 20(4), 82-106. http://hdl.handle.net/20.500.12323/3723

[54] Santos, M., Serrano, S. L., \& Manchón, R. M. (2010). The differential effect of two types of direct written corrective feedback on noticing and uptake: Reformulation vs. error correction. International Journal of English Studies, 10(1), 131-154. https://doi.org/10.6018/ijes/2010/1/114011

[55] Schneider, C. Q., \& Wagemann, C. (2007). Qualitative Comparative Analysis (QCA) and Fuzzy Sets. Barbara Budrich.

[56] Shahnazari, M. (2011). The role of working memory in second language reading comprehension. Unpublished doctoral dissertation. University of Auckland, UK.

[57] Sheen, Y. (2007). The effect of focused written corrective feedback and language aptitude on ESL learners' acquisition of articles. TESOL Quarterly, 41, 255 - 283. https://doi.org/10.1002/j.1545-7249.2007.tb00059.x

[58] Sheen, Y. (2010). Differential effects of oral and written corrective feedback in the ESL classroom. Studies in Second Language Acquisition, 32(2), 203-234. https://www.jstor.org/stable/44488127

[59] Sheen, Y., \& Ellis, R. (2011). Corrective feedback in language teaching. In E. Hinkle (Ed), Handbook of research in second language teaching and learning (pp. 593-609). Taylor \& Francis.

[60] Sheen, Y., Wright, D., \& Moldawa, A. (2009). Differential effects of focused and unfocused written correction on the accurate use of grammatical forms by adult ESL learners. System, 37(4), 556-569. https://doi.org/10.1016/j.system.2009.09.002

[61] Shintani, N., \& Ellis, R. (2013). The comparative effect of direct written corrective feedback and metalinguistic explanation on learners' explicit and implicit knowledge of the English indefinite article. Journal of Second Language Writing, 22, 286-306. https://doi.org/10.1016/j.jslw.2013.03.011

[62] Shintani, N., \& Ellis, R. (2015). Does language analytical ability mediate the effect of written feedback on grammatical accuracy in second language writing? System, 49, 110-119. https://doi.org/10.1016/j.system.2015.01.006

[63] Stake, R. E. (1995). The art of case study research. Sage Publication.

[64] Storch, N., \& Wigglesworth, G. (2010). Learners' processing, uptake and retention of corrective feedback on writing. Studies in Second Language Acquisition, 32(02), 303-334. https://www.jstor.org/stable/44488130

[65] The colleges of oxford university classics language aptitude test (Specimen of Written Test at Interview Issued 2010). Oxford University Press.

[66] Thornbury, S. (1997). Reformulation and reconstruction: Tasks that promote 'noticing'. ELT Journal, 51(4), 326-335. https://doi.org/10.1093/elt/51.4.326

[67] Trofimovich, P., Ammar, A., \& Gatbonton, E. (2007). How effective are recasts? The role of attention, memory, and analytical ability. In A. Mackey (Ed.), Conversational interaction in second language acquisition (pp. 171-195). Oxford University Press.

[68] Troia, G., Harbaugh, A., Shankland, R., Wolbers, K., \& Lawrence, A. (2013). Relationship between writing motivation, writing activity, and writing performance: Effects of grade, sex, and ability. Reading and Writing, 26, 17-44. https://doi.org/10.1007/s11145-012-9379-2

[69] Truscott, J. (1996). The case against grammar correction in L2 writing classes. Language Learning, 46 (2), $327-369$. https://doi.org/10.1111/j.1467-1770.1996.tb01238.x

[70] Truscott, J. (1999). The case for "the case for grammar correction in L2 writing classes": A response to Ferris. Journal of Second Language Writing, 8, 111-122. https://doi.org/10.1016/S1060-3743(99)80124-6

[71] Truscott, J. (2009). Arguments and appearances: A response to Chandler. Journal of Second Language Writing, 18 (1), $59-60$.

[72] Vygotsky, L. S. (1978). Mind in society: The development of higher mental process. Harvard University.

[73] Yang, Y., \& Lyster, R. (2010). Effects of form-focused practice and feedback on Chinese EFL learners' acquisition of regular and irregular past tense forms. Studies in Second Language Acquisition, 32(02), 235-263. https://www.jstor.org/stable/44488128

[74] Zhang, Z. V., \& Hyland, K. (2018). Student engagement with teacher and automated feedback on L2 writing. Assessing Writing, 36, 90-102. https://doi.org/10.1016/j.asw.2018.02.004

[75] Zheng, Y., Yu, S., \& Liu, Z. (2020). Understanding individual differences in lower-proficiency students' engagement with teacher written corrective feedback. Teaching in Higher Education, 1-21. https://doi.org/10.1080/13562517.2020.1806225 